\title{
Recent variation in concentration of dissolved sulfur species in Yugama, an active crater lake of Kusatsu- Shirane volcano, Japan
}

\author{
Y. KIKAWADA ${ }^{1 *}$, H. YAMAMOTO ${ }^{1}$ AND R. FUJINO
}

${ }^{1}$ Sophia University, Tokyo 102-8554, Japan

(*correspondence: y-kikawa@sophia.ac.jp)

Yugama, a crater lake of Kusatsu-Shirane volcano, Japan, is an active crater lake having subaqueous fumaroles at the lake bed. It is known that the Yugama water contains polythionates, and the variation in their concentrations is connected to the activity of the volcano [1]. Several observations and monitoring results suggest the volcano has been in the active periods since 2014. In this study, we discuss the recent variation in the concentration of sulfur species in Yugama and its relation to the volcanic activity of the Kusatsu-Shirane volcano.

The concentrations of polythionates in the Yugama water samples were determined as the differences between total sulfur concentration measured by ICP-OES and sulfate concentration measured by ion chromatography. This procedure is a simple way to grasp the variation of the total concentration of polythionates in the sample water.

The concentration of polythionates in Yugama water started suddenly increasing after the earthquake swarm with ground deformation at the summit area in 2014. At the same time, the oxidation-redox potential (ORP) of the Yugama water showed an increasing tendency. The polythionates concentration in Yugama water seems to vary synchronized with the ORP value. It is reported that the concentration of $\mathrm{H}_{2} \mathrm{~S}$ in fumarolic gasses around the summit decreased in 2014. The ORP value of Yugama water is probably controlled by the $\mathrm{SO}_{2} / \mathrm{H}_{2} \mathrm{~S}$ ratio in volcanic gasses supplied from subaqueous fumaroles into the lake water. Accordingly, it is strongly suggested that the variation in the polythionates concentration results from the changes in the $\mathrm{SO}_{2} / \mathrm{H}_{2} \mathrm{~S}$ ratio in the subaqueous fumarolic gasses. The higher $\mathrm{SO}_{2} / \mathrm{H}_{2} \mathrm{~S}$ ratio in the gasses might induce the production of polythionates and stabilize them in the lake water.

The concentration ratio of polythionates against the total sulfur species in Yugama water is a good indicator of the changes in the chemical composition of fumarolic gasses around the summit representing the state of the activity of the volcano. Based on this indicator, the Kusatsu-Shirane volcano became the most active in 2016 and maintains its activity relatively high until today.

[1] Takano (1987) Science, 235, 1633-1635. 